\title{
DE LA GENERACIÓN X A LA GENERACIÓN @. TRAZOS TRANSICIONALES E IDENTIDADES JUVENILES EN AMÉRICA LATINA*
}

\author{
MARICELA Portillo, MARITZA URTEAGa \\ YANKO GONZÁLEZ, ÓSCAR AGUILERA y CARLES FEIXA
}

\begin{abstract}
RESUMEN
En este artículo se discute la existencia de una generación @ en América Latina. A partir de cinco casos de jóvenes latinoamericanos -indios, migrantes, pingüinos, generación 2.0 y trendsetters - , problematizamos la noción misma de generación en los contextos sociopolíticos y culturales de la región. Identificamos algunos rasgos transicionales de la llamada generación $\mathrm{X}$ a la generación@ a partir de las identidades juveniles latinoamericanas que evocan empalmes o palimpsestos en las propias subjetividades de los actores que desde la política, el consumo, la desigual incorporación tecnológica, la migración y la neorruralidad dibujan las peculiaridades generacionales latinoamericanas.
\end{abstract}

PALABRAS CLAVE: GENERACIÓN X, GENERACIÓN @, IDENTIDADES JUVENILES, AMÉRICA LATINA

* El presente artículo es una versión revisada y ampliada del que se publicó en inglés en Feixa, Portillo, Urteaga, González y Aguilera (2012). «From Generation X to Generation @. Transitional Traces and Youth Identities in Latin America». In Ch. Henseler (Ed.): Generation X Goes Global. Youth Culture at the Turn of the Century. London \& New York: Routledge. 


\title{
DA GERAÇÃO X À GERAÇÃO @. ASPECTOS TRANSICIONAIS E IDENTIDADES JUVENIS NA AMÉRICA LATINA
}

\begin{abstract}
RESUMO
Este artigo discute a existência de uma Geração @ na América Latina. A partir de cinco categorias de jovens latino-americanos -índios, migrantes, pinguins, geração 2.0 e os trendsetters - problematizamos a própria noção de geração nos contextos sociopolíticos e culturais da região. Identificamos algumas características de transição da chamada geração X para a geração @, a partir das identidades juvenis latino-americanas que evocam articulações ou reciclagens nas próprias subjetividades dos atores, os quais, a partir da política, o consumo, o acesso desigual à tecnologia, a migração e a neoruralidade, estabelecem as peculiaridades geracionais da América Latina.
\end{abstract}

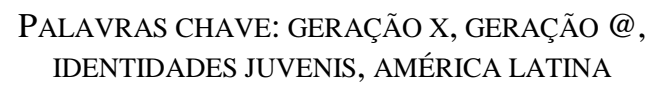

\section{FROM GENERATION X TO GENERATION @. TRANSITIONAL YOUTH AND IDENTITIES IN LATIN AMERICA}

\begin{abstract}
This article discusses the existence of a generation @ in Latin America. From five cases of American - Indian youth, migrants, penguins, generation 2.0 and trendsetters -, problematize the notion of generation in the sociopolitical and cultural contexts of the region. We identify some transitional features of generation X to generation @ from Latin American youth identities joints or palimpsests evoke in their own subjectivities of actors from politics, consumption, unequal incorporation of technology, migration and neo rurality give an idea of generational Latin American peculiarities.
\end{abstract}

KEY WORDS: GENERATION X, GENERATION @, YOUTH IDENTITIES, LATIN AMERICA 


\section{INTRODUCCIÓN}

P. ¿Cómo ve el panorama?

R. Como una lucha y una disputa entre un reloj que chequea el horario de ingreso de los empleados de una empresa, que es el reloj de Fox, y el nuestro, que es un reloj de arena. La disputa es entre que nosotros nos acomodemos a ese reloj de chequeo y Fox ${ }^{1}$ se acomode al reloj de arena. No va a ser ni lo uno ni lo otro. Tenemos que entender, él y nosotros, que tenemos que construir otro reloj de común acuerdo...

(El País, 25 de marzo de 2001)

EN 2001, HACE EXACTAMENTE una década, el escritor colombiano Gabriel García Márquez entrevistó al subcomandante Marcos, poco después de que éste entrase triunfante en el Zócalo - la plaza central de la ciudad de México - tras recorrer todo el país seguido por su pequeño ejército de jóvenes indígenas con el apoyo de numerosos jóvenes universitarios. Unas frases del líder zapatista llamaron particularmente la atención. Ante la pregunta sobre las perspectivas de las negociaciones de paz en Chiapas, Marcos respondía comparando el reloj de arena del tiempo indígena con el reloj mecánico del tiempo de la modernidad. Cuando García Márquez le preguntó por qué llevaba una linterna, un aparato de comunicaciones y un reloj en cada mano, su respuesta fue clarividente: «Con un reloj llegué a la selva y el otro es de cuando empezó el alto al fuego. Cuando las dos horas coincidan significa que se acabó el zapatismo como ejército y que sigue otra etapa, otro reloj y otro tiempo» (ibid).

En América Latina, la revuelta zapatista que emergió en Chiapas en enero de 1994, liderada por un viejo líder estudiantil al día de las nuevas tecnologías, protagonizada por un puñado de jóvenes indígenas, apoyada más tarde por jóvenes urbanos y universitarios de México y de otros países del subcontinente, acabó gozando de las simpatías de jóvenes de muchos otros países que se apropiaron de ella como su «revolución generacional», de la misma manera que la revolución cubana o la sandinista fueron emblemas para otras generaciones. Mostró la potencialidad de los jóvenes que se involucraron en esta revuelta. Se instalaron, sin pensarlo siquiera, en la primera movilización global que usó las tecnologías de la información como ninguna

1 Vicente Fox, primer presidente conservador de México (2000-2006). 
otra antes. Este movimiento ilustra muy bien la forma en que la generación $\mathrm{X}$ tuvo que lidiar con el advenimiento de internet.

La revuelta zapatista, más que las armas, utilizó las nuevas tecnologías de la comunicación para difundir sus consignas. Lo que algunos han llamado «la primera guerrilla posmoderna» se convirtió en un referente generacional para aquellos jóvenes que habían entrado en la juventud con la caída del muro de Berlín. En 1999, en Seattle, la década se cierra con una protesta contra una reunión de los poderes económicos mundiales, protagonizada por el llamado Movimiento de Resistencia Global. Paradójicamente, los «antiglobalizadores» son los primeros en utilizar las nuevas tecnologías de la era de la globalización: se trata de lo que algunos autores han llamado web movements (movimientos telaraña). Algunos años antes, en 1991, el escritor Douglas Coupland había popularizado el término «generación X» para referirse a una juventud marcada por las incertidumbres y las paradojas de la sociedad posmoderna, y por la falta de un sistema de valores sólido. Pero no es hasta la segunda mitad de la década cuando esta expresión empieza a aplicarse a movimientos juveniles de nuevo signo que surgen en América Latina (Feixa, 1997; Reguillo, 1998; Valenzuela, 1998; Urteaga, 2007), lo que coincide con la emergencia de las culturas juveniles como nodo central de los estudios culturales latinoamericanos (García Canclini, 2004).

En otro lugar (Feixa, 2000, 2005), hemos reflexionado sobre la transición del reloj de arena al reloj digital como metáfora reveladora de la juventud contemporánea, en la intersección entre la juventud moderna, nacida en los albores del siglo XX - la denominada generación $\mathrm{XX}$ - y la juventud posmoderna nacida al fin de siglo - la denominada generación @-. Desde esta perspectiva, la juventud tardomoderna, preposmoderna o transmoderna - la denominada generación $\mathrm{X}$ - aparece como el hito trascendental que separa, y al mismo tiempo conecta, ambas concepciones del tiempo (ambas formas de interacción entre juventud y sociedad). Si la última generación del siglo XX fue bautizada por el término «generación X», podemos individualizar a los jóvenes que transitan al siglo XXI como a la «generación @». Cabe destacar que las generaciones no son estructuras compactas, sino solo referentes simbólicos que identifican vagamente a los agentes socializados en unas mismas coordenadas temporales. Desde esta perspectiva, el término pretende expresar tres tendencias de cambio que intervienen en este proceso: en primer lugar, el acceso universal - aunque no necesariamente general — a las nuevas tecnologías de 
la información y de la comunicación; en segundo lugar, la erosión de las fronteras tradicionales entre los sexos y los géneros; y en tercer lugar, el proceso de globalización cultural que conlleva necesariamente nuevas formas de exclusión social a escala planetaria. Al categorizar a los jóvenes de hoy como «generación @», no pretendemos postular la hegemonía absoluta del reloj digital —o de la concepción virtual del tiempo-. Lo que pretendemos resaltar es el papel central que en esta transformación tienen las concepciones del tiempo en los jóvenes, que impacta la propia configuración del espacio social en el cual la juventud actúa. Por esos procesos, se reactualizan los modos de estar juntos y, dentro de ello, las modalidades de consumo cultural. El consumo de bienes audiovisuales es seguramente el sector del mercado que más claramente refleja estas tendencias de cambio.

De ahí que en América Latina constatemos una serie de empalmes; es decir, resabios de la generación X presentes en los jóvenes de inicios del siglo XXI, así como marcas de la generación @ en los jóvenes que tuvieron que «subirse al carro» de la superautopista de la información, ${ }^{2}$ en plena efervescencia de su juventud. La asimetría en los procesos de incorporación a la tecnología de los jóvenes latinoamericanos nos da como resultado generaciones atemporales o desfasadas en el tiempo. Así pues, podemos seguir dos rutas: un abordaje sobre la caracterización sociopolítica de las generaciones y otro desde una perspectiva sociocultural. La primera ruta debería encargarse de identificar y caracterizar las cohortes generacionales en América Latina, que son distintas a las que se establecen en Estados Unidos de Norteamérica o Europa. Los contextos sociopolíticos y económicos de la región obligan a problematizar las formas en que la generación X tomó forma en este continente. No podemos soslayar, en este sentido, que fue hija de una generación que sufrió las dictaduras políticas que azotaron a los distintos países latinoamericanos y que por supuesto impactaron de manera específica a los sujetos que crecieron en esa época de terror y barbarie. Los padres de la gen $\mathrm{X}$ tuvieron que migrar, exiliarse y, en muchos casos, fueron sistemáticamente desaparecidos. No es nuestra intención desarrollar esta problemática en este ensayo, pero nos parecía necesario subrayarla. En tanto los procesos de dictadura dieron paso a transiciones a la democracia de distinta intensidad en los países de la región y a profundas crisis económicas, la juventud apare-

2 Término popularizado durante la década de los noventa por Al Gore para referirse a internet. 
ció marcada como problema social, apática en lo relativo a lo político y como una gran incógnita respecto a su comportamiento futuro.

La segunda ruta, denominada perspectiva sociocultural, es la que seguiremos en este ensayo. Lo que haremos será mirar este palimpsesto generacional, producto de temporalidades superpuestas que configuran ciertas subjetividades juveniles latinoamericanas. Asumimos esta perspectiva, que resulta más compleja, y que nos planteará una dificultad para nombrar taxativamente a las generaciones. Delimitar las generaciones de jóvenes en América Latina no es una tarea fácil para los investigadores, pues implica considerar diversos contextos socioculturales en la conformación de los distintos modos de ser joven. En muchos países, regiones y localidades de América Latina las categorías como clase, etnia y género tienen pesos mucho más definitorios en la conformación de sus condiciones juveniles o juventudes. Parafraseando a Rosaldo (1991), y de manera exploratoria, este texto aborda estas relaciones como líneas que se intersectan en zonas contemporáneas transfronterizas con múltiples líneas como urbano, rural, región, global, migración, generación, nacionalidad, política, vestido, gustos musicales, etcétera, que complejizan aún más el análisis de la condición juvenil contemporánea en países como México y Chile.

Así pues, en este capítulo problematizaremos la generación X en América Latina a propósito del tránsito hacia la llamada generación @, en el entendido de que ambas generaciones quedaron atrapadas, por distintas circunstancias, entre dos tiempos dibujados en la metáfora del reloj analógico y el reloj digital. La generación X arribaba a su juventud cuando surgía internet en la segunda mitad de los noventa, mientras que la generación @ recién nacía en esos años. Considerando los desfases tecnológicos en América Latina, surgen estos empalmes que mencionamos anteriormente. Si bien generación X y generación @, son categorías construidas para contextos distintos al latinoamericano y responden a marcas culturales e históricas específicas del contexto de origen (Estados Unidos, países desarrollados y principalmente occidentales), este texto plantea que pueden ser útiles como puntos de partida para una discusión racional y crítica basada en la evidencia empírica de cada contexto social y cultural que descarte una noción hiperbólica de generación. Presentaremos el retrato de cinco actores juveniles emergentes en la transición del siglo XX al XXI, fruto de investigaciones en terreno realizadas entre ambos siglos en México y Chile, dos países situados a ambos extremos de la región: jóvenes indígenas, rurales, urbanos, estudiantes y trendsetters. 


\section{JóVENES INDIOS EN MÉXICO: DE MIGRANTES A MAZAHUACHOLOSKATOPUNKS}

Las implicaciones que tiene ser indígena en la ciudad de México son varias y múltiples: unas positivas y otras negativas, aunque son más las implicaciones negativas desde un punto de vista social, ... no nada más las instituciones te discriminan, sino socialmente existen ciertos prejuicios dirigidos hacia cualquier persona que se considere indígena. Por ello muchos no reconocen su condición de ser indígenas y tienen ciertos patrones de adaptación (Mario, 21 años).

El tema de la juventud indígena ${ }^{3}$ no ha sido central ni en la investigación ni en la política social. Entre las razones de este desentendimiento, está el reciente reconocimiento de un periodo etario dentro de los pueblos indígenas diferente de la infancia y la adultez. La emergencia de algo que puede denominarse período juvenil entre la población étnica que habita en los pueblos como en las ciudades se enmarca entre los vertiginosos y dislocantes cambios de los últimos veinticinco años en las dimensiones económica, tecnológica, social y cultural de la sociedad mexicana, los cuales están modificando sustantivamente las vidas diarias de las personas, y en especial de los/as jóvenes.

Identificamos cinco condiciones sociales en la producción de este sujeto joven emergente: el peso demográfico actual de los jóvenes en las sociedades étnicas mexicanas (censos años 1990, 2000 y 2005); la extensión de la obligatoriedad de la escuela secundaria y la introducción de la telesecundaria en zonas y pueblos indios; las estrechas relaciones entre las nuevas generaciones indias con los medios de comunicación - televisión y radio- y las nuevas tecnologías; la subversión zapatista que ha visibilizado a los jóvenes indígenas y acelerado la construcción de liderazgos políticos entre las nuevas generaciones; $\mathrm{y}$ los flujos migratorios de fines del siglo XX a nivel local, nacional y global, en donde la cantidad y la significación de los jóvenes indígenas es importante en la construcción de la denominada «cultura migrante» (Urteaga, 2008).

3 El término indígena en México oculta las 62 etnias realmente existentes en todo el territorio nacional, decidimos utilizarlo aquí, porque así los denominan los urbícolas y también las instituciones con las que interactúan. 
Ubicamos la presencia de los jóvenes indígenas en la Ciudad de México dentro de los procesos de desterritorialización que hoy caracterizan a ciudades mundializadas como Ciudad de México (Hannerz, 1998). La migración indígena es fundamental para entender la producción de juventud entre las etnias del desplazamiento ${ }^{4}$ en la ciudad. Bajo la etiqueta «jóvenes indígenas» se esconden diferencias de todo tipo incluyendo de clase, edad, origen étnico, educación, ocupación, profesión, expectativas, estilos de vida, y muchas otras, las cuales conforman prácticas culturales y espaciales urbanas muy diversas.

Los jóvenes de reciente migración a Ciudad de México ocupan los últimos escalones laborales: ellos, como albañiles, trazadores, fierreros, carpinteros, yeseros, marmoleros, tablarroqueros, pintores, impermibilizadores, electricistas, plomeros, aluminieros, herreros, limpiadores, mozos, soldados y ellas, como empleadas domésticas. Empleos a los que generalmente han accedido a través de las redes familiares y comunitarias de apoyo que las generaciones anteriores de migrantes indios construyeron como fuentes de recursos y empleo: «las redes de comunicación, de apoyo y como muchos las utilicen y se basen en ellas y en su condición de indígenas, para acceder a ciertos puestos... (y) a redes más fuertes de influencia. Hay comunidades que están muy bien organizadas, comunidades triquis, mixtecas, zapotecas; y en ese sentido, es benéfico considerarte zapoteca o indígena...» (Edgar). Estas redes son usadas y valoradas positivamente por jóvenes como Edgar (21 años, soltero, originario de San Andrés, Puebla), que llegan del campo a la ciudad a trabajar «en la construcción» y ahorrar algo de dinero para regresar rápidamente a sus pueblos pues «hay empleo», al que ellos (con una escolaridad de primaria) pueden acceder y ganar mucho más que en sus lugares de origen, a pesar de lo extenuante de las jornadas. O como Teresa (23 años, soltera, originaria de San Isidro, Oaxaca), quien llegó a través de su hermano mayor a trabajar como cocinera, y que en su tiempo libre ha estudiado la preparatoria y un diplomado en informática y gasta todo el dinero que gana en su persona. Para ellos, estas redes son una «opción que permite mejorar paulatinamente, o en el peor de los casos, por lo menos sobrevivir». Ellos rentan una habitación en la periferia de la ciudad o en los predios indígenas de la zona céntrica de la ciudad cerca o con familiares; ellas viven en las zonas

4 Por etnias del desplazamiento, Mora et al. (2004) entienden el desplazamiento territorial orientado al cambio residencial de los grupos sociales a fin de mejorar su calidad de vida. 
residenciales donde prestan sus servicios; ambos están muy vinculados a sus familias y pueblos de origen.

Sus tiempos y espacios de ocio están acotados por los días libres (sábado por la tarde o domingo). El espacio urbano se presta para el anonimato y la creación de estilos o formas de vida diferentes, situación que tensiona poco a poco la vida de los jóvenes migrantes en tanto se opone a las formas conductuales colectivas tradicionales de sus culturas de origen. La selección de sus lugares de encuentro y socialidad en la ciudad, así como las prácticas culturales y sociales que despliegan en el espacio público, expresan un fuerte arraigo a sus culturas de origen: parques, deportivos y espacios con mucho «verde», que de alguna forma recrean las maneras conocidas de «estar juntos» $y$ les posibilitan conocer a otros jóvenes parecidos a ellos y ellas con los cuales se sienten cómodos. Sin embargo, a diferencia de los pueblos, lo que estos jóvenes migrantes buscan en estos espacios son espectáculos culturales, musicales, cinematográficos, teatrales, así como lugares para ir a bailar, comer y estar entre amigos o con la pareja y poder ser jóvenes - consideradas como prácticas urbanas-. Dado que viven en espacios reducidos o ajenos - como en las residencias o en «las obras» donde trabajan (Sánchez Chávez, 2009)—, su persistente y constante concurrencia a espacios como la Alameda Central $^{5}$ ha demandado servicios y lugares de ocio cada vez más equipados y seguros para los jóvenes, implicando el ingreso del mercado en el ocio y su transformación en negocio. La interculturalidad básicamente se practica con jóvenes pertenecientes a otros grupos étnicos y casi nunca con los jóvenes mestizos, muy diferentes a ellos en sus prácticas y espacios de ocio.

Los procesos de discriminación y exclusión de las etnias en la ciudad son múltiples. El contexto urbano mexicano históricamente ha excluido la presencia indígena de la membresía urbana bajo la «falsa idea de que los indígenas pertenecen al medio rural y campesino, mientras que las ciudades son el espacio de lo cosmopolita, que asimila y elimina las diferencias culturales» (Escalante, S/F). Las prácticas discriminatorias van desde la publicidad en espectaculares (grandes carteles) como «para que el metro no huela a Indios Verdes», de una empresa de desodorantes que asocia en la mente de los mestizos que los indios son «cochinos» y «apestan»; otro cartel publicitario en el Periférico «No te pases el alto, no seas indio», que insiste en calificar-

5 Espacio público ubicado en el Centro Histórico de la Ciudad de México. 
los de «incivilizados», hasta la descalificación de los lugares públicos donde una buena parte de los indígenas jóvenes recién migrados o pobres pasea en sus tiempos libres. La Alameda Central, la Villita, el Zócalo capitalino, el bosque Chapultepec, las terminales de autobuses de la ciudad - entre otros - son para los mestizos e incluso para jóvenes indios de otros sectores sociales los lugares urbanos de «lo negado»: ir a la Alameda es ir a «gatear» o a «paisanear»; ir con la «macuarrada» o con los «nopalitos». 6

Sin embargo, a diferencia de los movimientos migratorios de antaño, durante los últimos años en estos y otros espacios públicos se han hecho visibles jóvenes migrantes con «fachas» espectaculares -que incorporan, hibridizando, elementos y códigos estéticos promovidos por el mercado y los medios, y por las subculturas juveniles urbanas circulantes-, nuevos gustos musicales y de diversión y a los que Gama (2007) y Sánchez Chávez (2009) denominan «mazahuacholoskatopunks». Estos jóvenes de ambos sexos han pasado de copiar a la creación de un estilo propio con el cual interactúan entre ellos y con otros jóvenes en la ciudad. También, a diferencia del pasado, los líderes indios en la ciudad - entre los que se encuentran jóvenes que en su mayoría cuentan ya con estudios universitarios-, apelando a su condición indígena, responden mediática y legalmente en la actualidad a las campañas empresariales e institucionales discriminatorias contra lo que consideran atenta contra la dignidad étnica.

Algunos jóvenes indios y migrantes también son cada vez más visibles ya que son universitarios que pertenecen a las nuevas generaciones altamente escolarizadas, algunos de ellos con maestrías y doctorados, ${ }^{7}$ entre las cuales las redes de apoyo étnico dejan de serles útiles para acceder a mejores puestos de trabajo y al logro de las nuevas expectativas generadas. Este pequeño sector ilustrado utiliza con mucho éxito la vulnerabilización de la condición indígena por parte del gobierno federal y los gobiernos estatales a través del acceso a

6 Gatear, paisanear significa mezclarse con los indígenas o provincianos. Macuarrada y nopalitos son términos discriminatorios que refieren a indígenas como personas de calidad inferior.

7 Algunas de las carreras que los jóvenes entrevistados y participantes en el Taller de Intercambio entre jóvenes indígenas y migrantes en la ciudad (CDI, abril 2006) estaban cursando en la ciudad son antropología, etnohistoria, lingüística, historia, geografía, filosofía, comunicación, música, artes plásticas y derecho. 
becas en programas de educación superior, ${ }^{8}$ sin dejar de pertenecer a las redes étnicas. Sin embargo, la pertenencia a estas redes comunitarias - y a los grupos y cargos de poder y decisión - no se hereda, ni se garantiza simplemente por haber nacido en los pueblos de origen: se gana, se trabaja, se construye asumiendo un compromiso con la comunidad a través de la asunción de cargos y otras responsabilidades comunitarias — como el tequio-, así como familiares — como «mano vuelta», «gozona», «guetza»-, que asumen diversos nombres en cada pueblo. Para estos jóvenes, la asunción paulatina de estos compromisos significa ir haciendo pública su voluntad de pertenencia étnica que posibilita una forma comunitaria de vida que «la ciudad no puede ofrecerles» y empezar a asumir que «uno existe gracias a la comunidad», principio contradictorio al individualista, que prevalece en la ciudad, donde «todo existe gracias a uno». ${ }^{9}$ Por otro lado, cumplir con estas obligaciones otorga «derechos sobre la tierra, aún viviendo en la ciudad, siempre y cuando se cumpla con lo anterior» (Ortega, 2001). Aquí nos encontramos con una institución formativa clave en la reproducción cultural de las etnias contemporáneas en México, así como con un aporte fundamental a la construcción de lo juvenil contemporáneo. Por un lado, se trata del impulso a los nuevos liderazgos indios en contextos nuevos y en los principios colectivos:

A los 14 años, Felipe fue a estudiar a Puebla entrando en contacto con una comunidad de jóvenes indígenas orgullosos de su identidad; comenzó a vincularse de manera más libre con sus orígenes: «No me siento a gusto con la camisa de citadino, me gusta esto, empezamos a aprender a trabajar como ellos, en el campo, y nos empezó a gustar meternos y empezamos a reacomodarnos en lo nuestro...». Tuvo que demostrar a los jóvenes triquis de la comunidad que «él no era un triqui de ciudad», reaprendiendo el idioma hasta manejarlo «como ellos», aprendiendo la historia de la comunidad, «lo que te hace regresar la mirada

8 Maestría en Lingüística Indoamericana (CIESAS y CDI); Maestría en Educación Indígena (UPN); Programa SNAEL Saberes (becas para estudios de posgrado a indígenas en la UNAM, CDI y Gobierno Estado de Chiapas); Programa de Becas Ford para estudios de licenciatura y posgrado; además de las actuales universidades indígenas o interculturales, algunas de la cuales operan en Sinaloa, Estado de México, Michoacán y la Huasteca (Pérez Ruiz, 2008:13). Programas de acceso a la educación superior creados después del levantamiento y las negociaciones zapatistas.

9 Disponible en: www.indigenasdf.org.mx/pueblos/21/sistemas-de-cargode-los-pueblos-indigenas. 
hacia el pueblo». Aprende sobre el «compromiso comunitario». En corto tiempo es conocido y reconocido entre los jóvenes de Santo Domingo y de otras comunidades aledañas y la asamblea de su comunidad lo elige como representante de la juventud entre los migrantes, un cargo estratégico para el reagrupamiento triqui en la ciudad. Como parte de la estrategia, forma con su grupo de amigos jóvenes de la comunidad el grupo musical «Emigración Triqui». «Necesitábamos nuestra propia música y músicos» en los eventos. Hace diez años están juntos por el compromiso comunitario basado en lealtades a las familias, a los cargos de la comunidad, a reciprocidades; y amarrándose como compadres, con el respeto afectuoso que esa relación entraña. «Tengo compromisos, hice compadres, voy a ser mayordomo, ya he pasado cargos, ya he estado haciendo obra pública, incluso en la ciudad, hicimos un puente vehicular ahí en la Colonia Nicolás Romero, donde vivo con varias familias triquis, náhuatl y totonacos», una «organización multicultural» que se formó en esa Colonia para hacer colectivamente frente a las dificultades de vivir en la ciudad. Está construyendo su casa a través del sistema de manos vuelta entre grupitos de compañeros jóvenes que necesitan apoyo para construir sus casas; y se hace tiempo para ir a jugar básquetbol con los jóvenes triquis cada domingo en el Toreo, porque los jóvenes son un sostén importante para su comunidad... 10

Por otro lado, socializarse en los principios comunitarios marca una gran diferencia con las maneras modernas de construcción de juventud. Sin embargo, en estos ámbitos y estructuras étnicas en la ciudad observamos, como otros investigadores (Pérez Ruiz, 2008), ciertas tensiones generacionales entre adultos/ancianos y jóvenes, que responden a las diferentes percepciones y expectativas que cada actor tiene sobre el proyecto de recomposición étnica y la participación de los actores en él. Los primeros, perciben a los jóvenes migrantes de manera ambivalente, como sostén importante para la comunidad (esperanza) y, a la vez, como fuentes del cambio (temor); mientras los jóvenes con una mayor educación y más tiempo en la ciudad tienen expectativas y demandas en su presente que no pueden ser satisfechas en el marco actual (y ancestral) de las relaciones de poder comunitarias sin que algo de esas relaciones se transforme en beneficio de la continuidad y la reproducción de los mismos pueblos étnicos. Algunos

10 Maritza Urteaga: Diario de campo («Felipe») de la investigación «Jóvenes indígenas en la ciudad. Diseño de taller para jóvenes indígenas en la Ciudad de México», para la Dirección de Fortalecimiento y Capacidades de los Indígenas (CDI), octubre 2004 a febrero 2005. 
sostuvieron que dentro de sus comunidades los jóvenes no contaban, tenían voz, pero no voto. ${ }^{11}$

El campo de batalla que es la ciudad, con toda su discriminación y modelo de éxito, hace que algunos jóvenes ilustrados desarrollen una cultura oposicional a partir de recurrir al núcleo de valores aprendidos en sus culturas parentales (comunitarias y familiares) con el propósito de resistir activamente los valores de la sociedad hegemónica. Algunos líderes jóvenes comprometidos con las nuevas organizaciones indias en la ciudad se sienten «herederos de la tradición» con «la responsabilidad de seguir manteniendo todos estos rasgos y patrones de identidad, para transmitirlos a las próximas generaciones» y «ya no caminar separados, dispersos, sino unidos, compartiendo una misma visión». ${ }^{12}$ Sin embargo, el estado de las investigaciones en torno a los jóvenes indios está muy lejos de homogeneizar situaciones que se viven de formas diversas dependiendo de una combinación de factores múltiples, entre los que se encuentra la subjetividad de los actores juveniles.

\section{JUVENTUD RURAL EN CHILE: DE LA SOLTERÍA AL METAL}

[yo] Escuchaba esa música [metal] cuando salíamos temprano de clases en Valdivia, íbamos a la casa de un amigo y sus papás trabajaban y ahí escuchábamos todo el rato esa música. [...] Yo me vestía con unos zapatos caña alta negros, un jeans negro apretado, un suéter debajo, negro, y una polera encima. Justo cuando ya no me vestía de negro, llegó una tienda que se llama 'Pecados' en Valdivia. Está en la Galería España, creo, y ahí llegaron gorros, poleras, todo. [...] Me gustaba la música y quería representarlo vistiéndome así. Fue por esa música, porque cuando yo llegué a Valdivia casi todos mis amigos escuchaban eso y fue como una forma para adaptarme a tener que andar con ellos, porque era como que a uno le dieran a elegir, si se metía a un grupo de hip-hop, o un grupo de cumbia o a un grupo de metal. Y yo decidí meterme a ese grupo (Edgardo).

11 Taller de intercambio de experiencias, abril 2006.

12 Entrevista a Rafael, diciembre 2004, y «Pronunciamiento» al Seminario Juvenil Indígena por un México sin Pobreza, Valle del Anáhuac, 9 y 10 de diciembre 2005. En este último evento se revela la creación de la Asamblea Nacional de Jóvenes Indígenas. 
En Chile, el proceso de «eclosión pública» de las juventudes rurales está estrechamente ligado a los procesos específicos que se vivieron en el campo posterior a la «contrarreforma» agraria llevada a cabo por la dictadura militar de Pinochet. Después de reprimir a las organizaciones campesinas, devolver una importante porción de tierras expropiadas bajo el gobierno de la Unidad Popular, el gobierno militar comienza una acelerada dinámica neoliberalizadora del agro. Licita predios reexpropiados a asignatarios de la reforma agraria o fiscales a parceleros particulares y vende otros a un grupo de empresas transnacionales que se instalan desde mediados de la década de los ochenta en la zona central para producir y exportar frutas.

En este contexto, en la zona central del país emerge masivamente un nuevo actor en el campo: los temporeros. Trabajadores estacionales de ambos sexos que sirven a la agroindustria de la fruta de exportación y que se componen principalmente de «campesinos desplazados de los fundos, antiguos beneficiarios de la reforma agraria abandonados a su suerte, los que perdieron sus parcelas, los que se vieron obligados a emigrar hacia pueblos o aldeas o hacia ciudades, los miembros de las familias de la pequeña agricultura campesina empobrecida» (Chonchol, 1996:385). A partir de esta realidad, comienzan a fraguarse las condiciones que permitieron la visibilidad identitaria de los segmentos más jóvenes de los/as temporeros/as que se enrolaron masivamente en estas labores. Aunque el fenómeno fue detectado tempranamente (cfr. Díaz y Durán, 1986), no fue hasta fines de la década de los noventa en que se estudió en forma específica (De la Maza, 1998), debido a la alta incidencia de jóvenes en estas tareas. Las diferencias agroecológicas y culturales tuvieron un importante papel segmentador de las realidades rurales de la zona central con respecto al sur y centro sur de Chile. Para el caso del sur del país, y específicamente para la Región de Los Ríos y de Los Lagos, el modelo neoliberal impactó fuertemente la economía y cultura campesina (pequeña agricultura), a través de la penetración capitalista de la agricultura comercial, pero lo hizo con intensidad a partir de la década de los noventa, con una agroindustria ligada a la pesca (salmonicultura) y el sector forestal (Amtmann, et al., 1998), que generó una fuerte destrucción de la producción parcelaria y un empobrecimiento de las economías campesinas tradicionales. Mutaciones inscritas bajo el rótulo optimista de «nueva ruralidad», cuyos bordes evidentes aparecen en la extensión abrupta del transporte y las comunicaciones, la desagrarización, la aparición de los «neorrurales», las segundas residencias o el turismo rural, una forma de terciarización económica. 
El conjunto de estos antecedentes colocan en el centro de la reflexión algo importante: la conflictiva constitución como actores sociales - al menos desde la década de los ochenta — de los jóvenes rurales de ambos sexos pertenecientes a estas ruralidades «alteradas». Ello debido, primordialmente, a la proletarización y el contacto con el medio urbano, pero también, y sobremanera, a la articulación con el mercado, la educación superior, la industria cultural y los medios de comunicación de masas, fundamentales en la juvenilización de la sociedad y la cultura desde la mitad del siglo XX en Chile y América Latina.

Asentados en un estudio etnográfico, ${ }^{13}$ basado en historias de vida del distrito rural-costero de Chaihuín, ${ }^{14}$ en el sur de Chile, queremos dar cuenta de algunos elementos contribuyentes a la formación de la identidad juvenil en este espacio, referido a la última generación de jóvenes en estudio operativa entre 1990 y 2003. Dicha identidad juvenil la contrastaremos con información perteneciente a las generaciones precedentes con el objetivo de ilustrar la dialéctica de dichas adscripciones identitarias en el tiempo. Históricamente - en el amplio espectro de sociedades basadas en la producción agrícola, ganadera y silvícola que ocupan un lugar subordinado en conjuntos estatales más amplios-, la juventud acostumbra a coincidir con una etapa de semidependencia social, caracterizada por una precoz inserción laboral y por un estatus subordinado de los jóvenes en el seno de la familia. Dado el carácter doméstico de las unidades de producción y consumo, todo está en función de su reproducción material y moral. La dominación patriarcal del cabeza de familia sobre los grupos dependientes (mujeres y jóvenes) se expresa en los sistemas de herencia y en el control sexual. Paradójicamente, los jóvenes, que constituyen una parte fundamental de la fuerza de trabajo, no tienen ni prestigio ni poder. Como compensación, ocupan un lugar central en el espacio lúdico de la comunidad y a menudo participan en muchos aspectos de la vida festiva (fiestas patronales) o recreativas (agrupaciones deportivas).

Realidad no muy distante a la que se experimentaba en el distrito rural de Chaihuín desde principios de siglo XX hasta bien entrada la

13 El que se inscribe en la investigación teórica y doctoral del autor (González, 2003 y 2004) y algunos trabajos convergentes a estos ámbitos de estudio (Feixa y González, 2003 y 2005).

14 Distrito de comuna de Corral situada en la Provincia de Valdivia de la Región de Los Ríos, en el sur de Chile. Tiene cerca de 1.000 habitantes dedicados a la recolección de peces y mariscos, labores forestales, pequeña agricultura y, últimamente, al turismo en pequeña escala. 
década del cincuenta del mismo siglo. Período en que predomina un tipo de adscripción juvenil contrastante con el mundo urbano en la medida que el marcador biológico (edad) perfila a un actor con escasa diferenciación con respecto al conjunto de la comunidad. La soltería es el marcador que sintetiza dicha condición: el estrecho intervalo que media entre la dependencia y la independencia a la unidad doméstica y el colectivo social mayor. La urgencia por incorporarse como agentes productivos y el obligado retraso de la emancipación familiar. En el caso de los varones, por una norma consuetudinaria, la llamada «ley de los 25 [años]», los compele a comprimir el tiempo de soltería y casarse velozmente.

Don Pascual — nacido en 1929 - sabía que su tránsito hacia la emancipación familiar y, por tanto, al término de su condición de «cabro» (niño-muchacho), tenía fronteras biológicas muy precisas, prescritas por la propia comunidad de Chaihuín: «según el reglamento, el hombre tenía que tener veinticinco años pa' [sic] poderse casar, porque tenía que ser un hombre maduro, que sepa hacer todo lo que había en un hogar. Hacer su casa, sobre todo eso es lo que se exigía en esos años. No podía ser más joven, porque dieciocho, veinte años para los antiguos era un niño todavía; aunque eran más maduros, porque un cabrito de diez o doce años comenzaba a trabajar en el monte, a trabajar con bueyes, que sé yo. Pero en esa época sólo después de los veinticinco se podía casar». Así, lo importante es que no solo la soltería articulaba su «niñez juvenil», sino que el dato vital se convertía en imprescindible para cambiar de estatus sociocultural, cuestión que el «joven» esperaba con ansias. El guarismo de veinticinco años aparece quizás como una muy conveniente negociación para el poder paterno dominante en relación a sus hijos, que, pese a cumplir duras tareas productivas, su dependencia se veía bastante alargada en el tiempo. Sin embargo, no puede haber una mejor transacción para estos últimos, puesto que el momento de la «liberación» tiene un límite objetivo que no da lugar a priori a la ambigüedad y la coacción por no abandonar la familia - fenómeno que don Pascual vivió intensamente antes de los veinticinco años-. La recompensa a esta larga espera no era menor, porque significaba en la mayoría de los casos de su generación la obtención de tierras y materiales para la construcción de una vivienda.

En la segunda generación estudiada operativa entre 1961 y 1989, las transformaciones de tipo productivo (labores de pesca y recolección de mariscos), la mayor oferta educativa y la modernización de la 
sociedad urbana desencadenarán una alteración en la soltería, reconvirtiéndola en una adscripción juvenil con una densidad biográfica mayor. El surgimiento del «pololeo», o noviazgo informal, es un dispositivo que ayuda a prolongar la soltería de esta generación, juvenilizándola pero, a su vez, abrevia esta juvenilización, por la mayor permisividad sexual que trae aparejado el pololeo, el que desemboca en una descendencia a sustentar. Las mujeres arribarán a esta «breve juventud» debido a la migración laboral (servicio doméstico). El pololeo, como constructo cultural urbano, y muchos bienes simbólicos de un mercado juvenil emergente (moda, música y revistas juveniles), serán apropiados y transmitidos por ellas a los varones. No obstante, la juvenilización de las muchachas será un proceso abortado debido a que al regresar a la comunidad de origen el prototipo identitario «joven y mujer» tendrá una precaria existencia.

Las constricciones materiales y simbólicas presentes en la comunidad para vivir la juventud desaparecen con los cambios producidos en la nueva relación campo-urbe, la que da paso a la extensión de las experiencias identitarias juveniles deslocalizadas, cuyos antecedentes se vislumbran desde las décadas del sesenta, con los abundantes enrolamientos al servicio militar por parte de los jóvenes y la alta ocupación en el servicio doméstico urbano por parte de las mujeres jóvenes. Sin embargo, en las décadas posteriores (80 y 90$)$ estas experiencias se radicalizan con la neoliberalización del agro, la modernización del transporte y las comunicaciones y la expansión educativa, que hacen a las nuevas generaciones acceder a la enseñanza secundaria, técnicoprofesional o al trabajo fuera de la comunidad en pesqueras y buques factorías internacionales. La mayoría son experiencias de deslocalización estacional, que implican el regreso e impactan a la comunidad de origen construyendo el fermento de un imaginario juvenil «juvenilizado»: légamo para la génesis de culturas juveniles.

La realidad descrita en forma precedente cambia radicalmente en Chaihuín desde finales de los años ochenta. Las nuevas generaciones en su periplo rural-urbano se juvenilizan básicamente a partir del consumo de los bienes simbólicos segmentados y multinacionales, de gran expansión territorial desde esta década. La industria cultural juvenil que comienza a operar desde los años 60 penetra muy tímidamente el campo. En los años ochenta los flujos comunicacionales crecerán y, a la par, las nuevas tecnologías de producción y reproducción musical y la televisión. «Todo llega sin que haya que partir», nos recuerda Martín-Barbero parafraseando a Virilio sobre el consumo de 
masas mediático y su extensión: la posibilidad de una urbanización con el consumo de productos juveniles sin necesidad de abandonar el campo. En el distrito de Chaihuín, la radiocasete se hace presente con intensidad, pudiendo seleccionar, grabar o mezclar lo que se escucha en las radioemisoras, abaratando los costos de uso y posibilitando la intervención creativa, en contraste con los caros discos o longplay de antaño y sus vitrolas y tocadiscos; o el monopolio de la escucha radial pasiva. Por ejemplo, la irrupción del walkman, o personal estéreo, masificados en los noventa, permite el transporte de las preferencias individuales de la urbe al campo y viceversa; los casetes menos costosos que los discos compactos pueden «piratearse»e intercambiarse por otros, ampliando exponencialmente la oferta y dotando de sentido al consumo musical como práctica creativa (Willis et al., 1990). Así, la música jugará un papel primordial, antes inexistente en la comunidad: la función de productora de identidades.

Las estrategias para lograr esta distinción, sin embargo, difieren de acuerdo a la posición ocupada en la estructura social, que quedan reflejadas en el consumo de cierto tipo de música con respecto a otra y la adscripción a una u otra representación de lo «juvenil». Para un grupo de jóvenes - la mayoría varones estudiantes y con aspiraciones de movilidad social y territorial—, las preferencias musicales apropiadas se mueven en torno a los gustos juveniles de las clases medias y populares urbanas: reggae, hip-hop, metal, tecno, pop latino o anglosajón romántico. En ellas y ellos se evidencia una lucha diferencialista. Son los que visitan asiduamente los taca-tacas, o futbolito de mesa, organizan cumpleaños e intentan (auto)sostener su identidad como jóvenes. Se «oponen en la tolerancia» a los que escuchan cumbia sound, los cumbiancheros o cumbiamberos y corridos mexicanos, por considerarlos poco modernos, antiguos y pertenecientes a una esfera social subalterna. Al interior de este grupo encontramos una variante más dibujada: los «metaleros», los que gustan de la genealogía heredera del hard rock, heavy metal, trash u otras variantes dentro del horizonte musical del rock pesado. Los metaleros tienen en Chaihuín un pequeño grupo de conspicuos representantes varones $-\mathrm{y}$ en menor medida mujeres-, que retroalimentan su estilo a partir del contacto directo con la urbe por su condición de estudiantes o a través de parientes que vienen de la ciudad. En sus esporádicas estadías en Valdivia asisten a algunos conciertos, se reúnen con sus compañeros de clase a escuchar música, visitan disquerías y comercios especializados en vestimenta y artículos relacionados con sus filiaciones estéticas y 
musicales. El proceso de «conversión a metalero» es bastante claro. Se inicia a partir de las experiencias urbanas en el entorno educativo. Una vez en la comunidad, se presentan los problemas de continuidad identitaria. El primero estriba en la marcada reactividad del mundo adulto para con la escenificación estética de sus preferencias y, en algunos casos, como Edgardo, esta reactividad es mucho más acentuada habida cuenta de la activa observancia religiosa de la madre, miembro de la iglesia evangélica de la comunidad y que llega a satanizar literalmente sus gustos. Pese a estas restricciones, los muchachos afines a la «onda metalera» en Chaihuín intentan sortear las presiones familiares y comunitarias ocultando sus preferencias más sancionadas (como el atuendo) y estableciendo lazos de asociatividad y complicidad, intercambiando casetes, afiches, ropa y actualizando sus últimos hallazgos musicales. Sin embargo, su «resistencia» se ve torpedeada por la escasa y atomizada población juvenil en la localidad, lo que reduce sus posibilidades de aglutinamiento y mantención de una identidad colectiva intensa y duradera en el espacio propio, constriñéndola a la esfera individual y deshaciéndose de los elementos más conflictivos para su entorno inmediato.

En este contexto se plantea con intensidad la dinámica identitaria vivida por este segmento de la población juvenil rural, representada en las estrategias adaptativas y en los reacomodos constantes de su identidad, en una fricción constante entre el «afuera» y el «adentro» y cuya síntesis se resuelve a partir de los retazos culturales transportados de la urbe a la localidad y en la apropiación y creación de espacios liberados para la expresión y experimentación de dicha condición juvenil. En este sentido, la emergencia de estas identidades juveniles es una hipérbole del propio reacomodo de las interconexiones rurales y urbanas en Chile. El largo proceso constitutivo de culturas juveniles en el mundo urbano del país desde los años cincuenta (coléricos, carlotos, sicodélicos, revolucionarios, etcétera) es inexistente en el mundo rural hasta los años noventa. A partir de allí, parece experimentarse una compresión histórica, un salto sociocultural abrupto que, en menos de una década, produce jóvenes «juvenilizados». En este sentido, los flujos comunicacionales y la rápida modernización (proyectos de desarrollo, expansión educativa, terciarización, etcétera) inclinan una balanza que, al menos hasta la década del setenta, estuvo equilibrada en relación al peso cultural de la urbe versus el campo en la configuración identitaria de los actores rurales. 


\section{JÓVENES ESTUDIANTES EN CHILE: LA GENERACIÓN PINGÜINA ${ }^{15}$}

Eran los primeros días de abril de 2006, y en los salones de la Intendencia Regional de Valparaíso se realizaba un seminario sobre la situación de la educación en la región. Durante los debates quedaba en evidencia la sensación de impotencia y abandono en que se desarrolla la tarea educativa de los centros de enseñanza pública. No sin cierta tristeza, los educadores señalaron en más de una oportunidad que en sus colegios la enseñanza queda en un segundo plano, porque es más importante «intervenir» en situaciones de consumo de drogas, culturas de la violencia a nivel familiar y comunitario, «y otras problemáticas psicosociales» que afectan a los estudiantes de los liceos de la región. Sin duda, un diagnóstico desalentador, pero que no hacía presagiar la movilización estudiantil más grande de todos los tiempos que ocurriría pocos días después. Si hemos optado por analizar en profundidad el caso de las movilizaciones estudiantiles del 2006, protagonizadas durante los meses de mayo y junio por los estudiantes secundarios, se debe a que consideramos que nos encontramos ante un verdadero acontecimiento. Es decir, una revolución simbólica que implica una transformación de lugares, una redefinición de los códigos sociales, una impugnación de las relaciones sociales y la creación de símbolos que ponen en duda el propio sistema de representaciones sociales hegemónico (De Certeau, 1995). Construir de esta manera la «rebelión pingüina» pone el acento en las dimensiones simbólico-culturales que permiten al mismo tiempo presenciar las modalidades en que lo social se vuelve visible, mediante la problematización de aquellas naturalizaciones y reificaciones que cotidianamente pasan desapercibidas ante nuestros ojos, así como analizar las reubicaciones de los lugares de enunciación en que se emplazan los distintos actores de un conflicto, expresando de esta manera nuevas relaciones de fuerza, usos diferenciados y diferentes de los discursos sociales, constituyendo en estratégico el control de dichas codificaciones y matrices discursivas. ${ }^{16}$

15 El calificativo de pingüino para referirse a estudiantes secundarios tiene un doble origen: en la similitud del uniforme escolar obligatorio con los colores del pingüino (oscuro con camisa blanca), y en la existencia de un suéter para estudiantes que utiliza un pingüino como marca.

16 Hacemos referencia a la forma discursiva en que la relación social adultos-jóvenes ha sido codificada en la tradición académica, mediática $\mathrm{y}$ de narrativas sociales a lo largo de todo el siglo XX, particularmente 
Es así como la «rebelión de los pingüinos», ${ }^{17}$ lejos de quedar reducida a una expresión de los desajustes socioestructurales del «sistema educativo», emerge aquí como un «estado naciente» (Alberoni, 1984). Es decir, un proceso social en el cual se despliegan prácticas y significados culturales que expresan las dinámicas de cambio y continuidad en un lugar y momento temporal específico, y que en términos metodológicos implica articular dimensiones objetivas y subjetivas que producen el conflicto, focalizando, por tanto, el análisis no sólo en las institucionalidades sino que también en los procesos constituyentes de grupalidades.

Los jóvenes estudiantes chilenos de ambos sexos se han constituido en los últimos años como el actor juvenil de mayor visibilización y articulación pública. Es más, las movilizaciones estudiantiles que se desarrollan en los meses de mayo a junio de 2011 pueden ser entendidas como parte del proceso de (re)emergencia, visibilización y maduración del movimiento estudiantil que durante la década de los noventa prácticamente se había diluido en muchos lugares de Chile. Un desafío adicional se presenta para el análisis de la generación pingüina, aquella que desde el 2000 en adelante se ha socializado políticamente en el movimiento estudiantil secundario, y que la sintetizamos en la siguiente formulación: las claves teóricas y conceptuales para leer el vínculo entre juventud y política, ancladas en la noción de cultura política juvenil y que enfatizan el plano de los imaginarios, simbolizaciones y representaciones de la política en su variante institucional, han llegado a su límite interpretativo y se requiere analizar aquellas dimensiones políticas que atraviesan y desarrollan las cultu-

alrededor del eje juventudes y política. Estas operaciones de disputa por el significado son las que definen las actuales formas de acción colectiva y de movimientos sociales en la contemporaneidad. Un análisis de los discursos sociales sobre la juventud en Chile, particularmente en el período de la transición chilena (1988-2000), se puede ver en Aguilera, 2003.

17 Fue común durante el proceso de movilización emprendida por parte de los estudiantes secundarios que se recurriera a diversas formas para nombrar el acontecimiento en curso: «revolución», «rebelión» y «movimiento» fueron las más usadas. Para efectos de este trabajo, y siguiendo una clásica distinción establecida por Camus entre el revolucionario y el hombre rebelde (1957), hemos optado por el calificativo de rebelión en tanto observamos que más que una lucha por una idea establecida, se trató de una movilización política que buscó instaurar, dado el contexto social, cultural y económico, una «posibilidad de idea». 
ras juveniles, y que aquí conceptualizamos como política de las culturas juveniles (Aguilera, 2010). Desde esta perspectiva, observamos un conjunto de procesos socioculturales que acompañan la constitución de una generación de jóvenes a partir de su experiencia compartida como participantes del movimiento estudiantil en esta primera década del siglo XXI.

Una primera característica evidenciada dice relación con los tiempos y espacios de la política. Mientras la política de los adultos espacializa en un solo lugar su práctica (el parlamento, los partidos políticos), la política cultural de los jóvenes la escenifica en la cotidianeidad (sus cuerpos, su sociabilidad, sus territorios más próximos). $\mathrm{Y}$ por otra parte, mientras la temporalidad política del mundo adulto se refiere a un largo plazo (un mañana mejor), la política cultural juvenil la instala en el corto plazo (un presente mejor). Esta otra configuración cultural es la base de muchos de los desencuentros de los actores juveniles y adultos cuando negocian la resolución de los conflictos. ¿Por qué esperar tanto tiempo cuando las reformas se pueden hacer hoy? Este parece ser el argumento generacional juvenil ante el mundo institucional.

Una segunda característica es la ampliación de los límites espaciales de la política, y que encuentra en los territorios de las nuevas tecnologías un frente de combate de doble significación: como espacio de constitución de la acción colectiva juvenil y que posibilita la toma de acuerdos entre diversos actores juveniles y la respectiva difusión de las actividades. Aquí es clave la web 2.0 (fotologs, facebook, twitter) y las nuevas tecnologías se presentan como un nuevo lugar de conflictividad y apropiación de recurso, en donde la información y circulación del conocimiento (contrainformación, medios de comunicación juveniles, asociaciones de software libre) se vuelven centrales en la práctica estudiantil.

Finalmente, una visibilización de las nuevas formas de exclusión a nivel planetario y que en el caso de los jóvenes pingüinos se traducen en sus reivindicaciones por tener una relación más simétrica y democrática con el mundo adulto de las escuelas y que vinculamos aquí con las demandas por el derecho al reconocimiento y la participación en la toma de decisiones que les afectan directamente (gobierno escolar, horarios de clases, actividades complementarias), así como en el respeto a sus opciones sexuales que en las escuelas se viven de manera mucho más restrictivas debido a las visiones biomédicas que perduran en muchas de las instituciones escolares. No es casual que en 
las tomas de escuelas secundarias, el autogobierno estudiantil y la vivencia de una sexualidad sin tapujos sean las situaciones más llamativas: una suerte de resistencia simbólica a la experiencia habitual que les ofrece la institución escolar.

Lo ocurrido en esos casi dos meses del 2006 reubicó los términos de la conversación social entre juventud y política. Sin embargo, poco ha sido el balance sobre el después en términos de los propios actores juveniles. O más precisamente, sobre las formas en que la rebelión pingüina impactó en la cotidianeidad juvenil y sus proyecciones posteriores en términos de involucramiento político. Y aun cuando no ha sido propósito en este análisis la pregunta por el después, o postrebelión pingüina, es necesario introducir algunas reflexiones que permitan leer interpretativamente lo que cambió en términos de subjetividad juvenil a partir del proceso de movilización desarrollado en ese invierno de 2006.

En primer lugar, la desarticulación y desmovilización juvenil dio paso a un proceso de reencantamiento con lo público que aun cuando no ha tenido una trayectoria única, ha venido impactando en múltiples registros la práctica asociativa en la sociedad chilena. En segundo lugar, y derivado de las experiencias del 2006 y de años posteriores, confirman la refundación ética de la política en lo que al mundo juvenil se refiere. Esta refundación se expresa en que las redes de interacción y socialidad juvenil se constituyen en registros de politicidad que se activan cuando imperativos éticos así lo proponen: la educación pública, el cuidado al medioambiente o el respeto a la diversidad sexual, se han constituido en exigencias éticas que vienen movilizando a miles de jóvenes chilenos. En tercer lugar, como la política se juega en lo cotidiano, en la fundación de lazos y relaciones de reciprocidad, respeto y cooperación que se viven en el día a día, los lugares de militancia y participación política, social y cultural de los/as jóvenes pingüinos se multiplican de manera exponencial. Aun cuando muchos de los dirigentes del 2006 continuaran estudios universitarios, no ha sido la universidad «el lugar» en que se participa o se expresa una determinada militancia. Centros culturales, movimientos de pobladores sin casa, voluntariados o partidos políticos constituyen en la actualidad algunos de los múltiples registros de la militancia juvenil postpingüina.

Quizá no sea mucho para análisis maximalistas. Pero en el devenir del actor juvenil constituyen puntos de inflexión que esta vez no sólo impactaron a la propia juventud sino al conjunto de la sociedad chilena en su pregunta por los límites y posibilidades de la conflictiva 
y nunca acabada construcción del orden deseado, como bellamente definió a la política el sociólogo Lechner (1998). Y esa interrogante, a cinco años de la rebelión pingüina, sigue siendo ampliada y profundizada por la acción colectiva de jóvenes y no tan jóvenes en Chile.

\section{JóVENES TRENDSETTERS EN MÉXICO: DE VANGUARDISTAS A EMPRENDEDORES}

Te enteras de cómo es en realidad... Un chavo que siempre ha estudiado en escuelas caras hace un documental de los reventones en Tepito y puede que se ponga a investigar y lo haga bien, pero no ha vivido algo así y es difícil que tenga esa idea real de cómo sucede ¿no?, o lo ve desde afuera. Entonces escribe un documental super oscuro porque él lo ve así. Pero la gente que lo está viviendo, que está en el «reventón», está fascinada ¿no? El estar en todos los ambientes, reventar y conocer mucha gente, ir a lugares distintos, desde ir a una cantina donde van sólo señores de cincuenta o sesenta años, hasta estar en un «rave» o en cualquier tipo de fiesta implica que conoces de qué se trata (Guillermo, diseñador de arte, escenografía y decoración).

Trendsetter es un categoría del marketing que significa «posicionados en la tendencia», de estilos de vida por venir o tendencias. Sin embargo, a falta de un término mejor, lo usamos para referirnos a aquellos jóvenes integrantes de la categoría de personas que Hannerz (1998) denomina «especialistas de la expresión» o «personas que se ocupan de la cultura» que viven en las ciudades mundializadas. Los trends son jóvenes nacidos en la ciudad y tienen entre veintiún y treinta y dos años; son solteros, sin hijos y viven con su familia de origen o comparten departamento con algún familiar. Se especializan en algunas actividades de tipo expresivo con un marcado sello generacional que trasciende sus orígenes de clase (el límite inferior es el de clase media baja); se concentran en carreras creativas como diseño (gráfico, textil, industrial, arquitectónico, de moda, joyería, mobiliario, etcétera), publicidad, arquitectura, comunicación, artes plásticas, cine, video, e incursionan en otras especializaciones que fomenten su creatividad y complementen su formación como actuación, locución, promotoría y difusión cultural, fotografía, serigrafía, arte visual y sonoro, entre otros. Sus productos culturales son artístico-funcionales a la vida mo- 
derna en la ciudad y su trabajo creativo es para cierto segmento del mercado. No son contrarios a lo comercial, consideran que se puede crear en lo comercial y se puede vivir de lo que se trabaja y hace creativamente. Desde el marco organizacional del «mercado» (Hannerz, 1998), los trends pueden ser ubicados como vendedores de ciertos productos culturales novedosos, más precisamente, son generadores de nuevas demandas entre clientes que están a la caza de bienes, servicios e ideas innovadoras para luego comercializarlas en gran escala a través del mercado.

Desde el marco «forma de vida», los trends se ubican de una manera particular entre los generadores y difusores de novedosos estilos de vida y de trabajo. Si bien comparten con las vanguardias ciertas concepciones sobre el trabajo - como placer y obtención de satisfacción estética y como innovación-, lo que los particulariza o identifica de manera distintiva es la combinación de creatividad y capacidad emprendedora que he denominado "pasión emprendedora». Esto es, tienen la capacidad de tomar el riesgo de emprender, en el sentido ejecutivo del término, nuevas ideas y difundirlas entre nuevos públicos y mercados a partir de asociarse con otros creativos para trabajar, crear y proyectar. Las formas de asociación con otros son muy diversas, pero tienen en común conformar colectivos autogestionados alrededor de proyectos creativo-empresariales que terminan cuando los proyectos se acaban. Viven, trabajan y construyen sus circuitos de diversión entre el Centro Histórico y las colonias Polanco, Condesa y Roma, San Rafael, Escandón, Santa María la Ribera, zona históricamente urbanizada de la Ciudad de México. Se consideran urbícolas y sienten que su fuente de inspiración creativa está en esa diversidad étnica y social del centro de la ciudad y no en la periferia donde habitan los sectores altos, medios altos y los sectores más pobres. Su apropiación del espacio urbano es metropolitana, con rutas de ocio que incluyen desde lugares urbanos tradicionales (cantinas, pulquerías, circos, plazas, heladerías, taquerías, tianguis), abandonados (casas, teatros, vecindades), undergrounds (bares, antros, terrenos baldíos en donde se instalan ambulantes, etcétera) hasta más comerciales (plazas comerciales, cines, restaurantes, cafeterías) o centros culturales (museos, casas de cultura, videoclubes, galerías, salas de exposición), en donde confluyen diversidad de jóvenes y personajes. La ciudad es valorada en su posibilidad de encontrarse e interactuar con otros muy distintos a ellos mismos.

Algunos sostuvieron que su trabajo consiste en crear y que mucho de lo que vivían en la metrópoli les servía como medio para crear 
«cosas» y ambientes o conceptos imaginativamente. Para Iván se trata de captar y emular en sus productos la improvisación, los missused o las maneras incorrectas de usar las cosas y el trastocamiento de los espacios y objetos que es realizado por las personas de la vida real.

De repente decidimos un día al mes irnos realmente a caminar al Centro entre los ambulantes. Los ambulantes son una energía extraordinaria, desde cómo montan su puestito hasta cómo se manejan. Caminamos por las calles para ver si encontramos un mal uso de las cosas, eso nos gusta mucho. De repente un día pasamos por el mercado y había una persona sentada en popotes, horizontales, y de repente fue, así de claro: tiene una estructura y se generó, con Mauricio Limón, un mueble que funciona a partir de popotes y fue un accidente que vimos a alguien sentado en un bonche de popotes horizontales. Claro vamos a hacerlo un mueble. Caminamos el Centro en búsqueda de accidentes... Por ejemplo, ahora, estamos investigando sistemas flexibles, contenedores que tienen la capacidad de volverse casi un maletín, [idea] que surge del ambulantaje, de esta capacidad de tener un trapo y de repente ya salieron corriendo con toda la mercancía, esta capacidad como de la navaja suiza, de estos sistemas que tienen... multifuncionalidad definitivamente. Ahorita estamos generando dos, uno, como una vivienda nómada, que literalmente te puedes llevar este contenedor y ahí vas sacando tu cama, tu baño... y otro, trabaja a un nivel muchísimo más chico, un maletín, del cual sacas como ciertas herramientas para navegar en la ciudad (Iván, ludens).

Los trends son un segmento juvenil puente clave entre las vanguardias culturales, estéticas, intelectuales y subculturales y los sectores más avanzados del mercado (trends-minoría temprana y adoptadores tempranos), quienes, a su vez, son los encargados de diseminar los cambios y patrones culturales a lo largo de la urbe. En esta especie de corredor que abren entre estilos de vida de sectores de la población tan diversos, los trends funcionan como un «territorio de flujo» de ideas, elementos culturales y simbólicos y materiales con los que se construyen a sí mismos como innovadores, introductores de cambios o transformaciones en los modos de trabajo, ocio, consumo de objetos y espacios, modos de estar juntos, esto es, en los estilos de vida. Los trends «lanzan proyectiles», provocan reflexiones e inquietudes en otros, generándoles necesidades en sus exploraciones y/o experimentaciones a las ideas e inquietudes que tienen. En este proceso van siendo «contagiados» por el otro y/o van contagiando al otro y generando esta simbiosis/infiltración creativo productiva del uno al otro. Los jóvenes trends estudiados pertenecen a varios sectores sociales, y 
ello, si bien delimita sus formaciones y campo de acción, su actitud es la misma: la innovación, la pasión emprendedora que se manifiesta de manera creativa y hedonista en los productos que exponen/venden y que intentan adelantarse a lo que todavía no hay. Las tendencias encontradas entre los trends en el 2004 están aún en curso, ${ }^{18}$ tiñendo varios estilos de vida citadinos.

\section{JóVENES DIGITALES EN MÉXICO: LA GENERACIÓN 2.0}

Plantearemos acá la emergencia en México de lo que nosotros denominados generación 2.0. Para ello describiremos a grandes rasgos la situación de la juventud mexicana y su acceso a internet. En un segundo momento, planteamos el concepto de generación y su utilidad heurística para la caracterización de un grupo social determinado. Finalmente, describimos las características de la generación 2.0 en México y su potencialidad generadora de nuevas formas de participación política en el futuro próximo.

México es un país de jóvenes. Así lo demuestran los datos más recientes, según los cuales, la mitad del país tiene menos de 26 años (INEGI, 2011). En este país, el 93\% de los hogares tiene televisión. Paralelamente, el acceso a las tecnologías de la información también ha ido incrementándose en los últimos años. ${ }^{19} \mathrm{Si}$ bien es cierto que la brecha tecnológica sigue imprimiendo diferencias brutales entre la población que no accede a la tecnología y la que sí, es innegable también el hecho de que amplios sectores de la población, sobre todo en sectores urbanos, ${ }^{20}$ están conectados. Según datos del último estudio de la AMIPCI (2011), en 2010 el número de internautas alcanzó los 34.9 millones; es decir, de cada 100 viviendas en México, 29 poseen una computadora y el $70 \%$ de la población que tiene computadora en casa, tiene acceso a internet. Sobresale el dato de la población joven con acceso a internet. De nuevo, según el mencionado estudio, el $27 \%$ de la población que cuenta con servicios de internet tiene entre doce y diecisiete años y el $23 \%$ tiene entre dieciocho y veinticuatro años. Si sumamos los porcen-

18 Estoy nuevamente investigando (2011) este segmento en los campos de las artes visuales, música, editorial y espacio virtual.

19 En diez años se ha triplicado la posesión de computadoras en los hogares mexicanos, por sobre la TV y la radio (AMIPCI, 2011).

20 El servicio de internet en los hogares tiene una mayor penetración en ciudades con más de 100.000 habitantes (AMIPCI, 2011). 
tajes, la mitad de los usuarios de internet en México son jóvenes (entre doce y veinticuatro años). Este último dato plantea nuevas interrogantes a quienes venimos interesándonos en la relación de los jóvenes con los medios de comunicación. De manera puntual, nos obliga a mirar lo que ocurre en el amplio ecosistema mediático que se conforma hoy con el agregado de internet, celular y videojuegos.

Martín-Barbero (1996) sostiene que asistimos a la emergencia de culturas juveniles cambiantes que nos hablan de una ruptura generacional sin parangón en la historia. Este autor dice que los jóvenes han logrado conformar un nuevo sensorium ${ }^{21}$ a partir sobre todo de las nuevas realidades que los medios en particular, y las nuevas tecnologías en general, ofrecen como mediadores de la experiencia social. En este mismo sentido, Feixa desarrolla el concepto de generación @ (2001), que refiere a los jóvenes que constituyen la primera generación del siglo XXI y que se caracteriza por «tres tendencias de cambio: en primer lugar, el acceso universal - aunque no necesariamente generala las nuevas tecnologías de la información y de la comunicación; en segundo lugar, la erosión de las fronteras tradicionales entre los sexos; y en tercer lugar, el proceso de globalización que conlleva necesariamente nuevas formas de exclusión social a escala planetaria». Así pues, una generación se caracteriza por una serie de elementos constitutivos que aglutinan a un grupo de sujetos que comparten un tiempo y espacio. Sostenemos, siguiendo a Ortega y Gasset (1970), que este concepto tiene un importante potencial explicativo para comprender una época. No vamos a entrar en detalles respecto al pensamiento de este autor; sin embargo, nos parece útil rescatar algunos aspectos que el autor plantea y que nos ayudarán a caracterizar la cuestión generacional. Una tiene que ver con la sensibilidad vital, otra con lo que denomina espíritu del tiempo y el último con su distinción entre coetaneidad y contemporaneidad. El espíritu del tiempo asociado a las ideas mayoritarias de la época puede entenderse como ese telón de fondo en el que los sujetos sociales se mueven en el mundo. Desde que el individuo nace se encuentra inmerso en una realidad social en

21 El sensorium es esta nueva forma de percibir la experiencia total, en cuya conformación la televisión ha jugado un papel determinante, como antes fueron importantes en este sentido el cine y la radio, ahora «con la televisión toma forma otro sensorium: en la ciudad diseminada el medio sustituye a la experiencia o mejor constituye la única experiencia simulacro de la ciudad global» (Martín-Barbero, 1996). 
la que ha de transcurrir su existencia, conformada por un sistema de convicciones que ha sido construido socialmente a través del tiempo. Desde una perspectiva construccionista, se explica cómo se genera ese conocimiento socialmente y, desde una perspectiva más antropológica, se diría que ese sistema de convicciones está definido por la cultura. El espíritu del tiempo nos sirve para explicar esta realidad social por la cual transita el sujeto y que le permitirá moverse siempre en un marco de convenciones sociales, creencias y tradiciones que han sido acordadas mayoritariamente por el grupo al que pertenece y que, en conjunto, están definidas culturalmente.

Por otro lado, Ortega y Gasset (1970) introduce una distinción que nos ayuda a precisar el término generación. Es la diferenciación que establece entre los términos coetaneidad y contemporaneidad. A este respecto, señala que en una misma actualidad histórica coexisten simultáneamente sujetos con diferentes edades. Conviven pues niños, jóvenes, adultos y ancianos. Si comparten un mismo tiempo son contemporáneos. Sin embargo, contribuyen a formar el mundo de un modo diferente porque no son coetáneos. Se es contemporáneo de quien comparte nuestro mismo tiempo, pero no todos los que compartimos el mismo tiempo somos coetáneos. La generación está definida por los criterios de coetaneidad: «El conjunto de los que son coetáneos en un círculo de actual convivencia, es una generación» (Ortega y Gasset, 1970). Esto quiere decir que en la visión orteguiana, si a toda generación le corresponde una dimensión en el tiempo histórico, le corresponde también una dimensión en el espacio. Constituyen una generación aquellos individuos que comparten comunidad de fecha y comunidad espacial. Pero aquí habría que introducir una aclaración. Para este autor, la edad constituye un cierto modo de vida que no se restringe a una fecha, sino a una zona de fechas. Los criterios de coetaneidad estarían regidos por esta zona de fechas. ${ }^{22}$ La generación estaría caracterizada por grupos de sujetos que tienen más o menos un cierto rango de edad y un cierto contacto vital. Ortega y Gasset sostiene que la generación histórica está compuesta de dos clases de hombres: unos que están en fase de gestación o creación (entre treinta y cuarenta y cinco años) y otros que están en fase gestionadora o al mando (entre cuarenta y cinco y sesenta años). Ambas generaciones están empalmadas, unas

22 Algunos autores fijan el rango de edad de las generaciones en quince años, como es el caso de Dromel, y otros, como Mannheim, creen que es de treinta años. 
instaladas en el mundo que han construido, otras creándolo. Las generaciones no son, como sostiene Feixa (2004), estructuras compactas, sino referentes simbólicos que identifican vagamente a los agentes socializados en unas mismas coordenadas históricas.

Según los datos de la AMIPCI e INEGI, los usuarios de internet en México son mayoritariamente jóvenes urbanos. Coincide también con los datos del World Internet Project, ${ }^{23}$ que señala que el $40 \%$ de los usuarios de internet en México son menores de diecinueve años. Asistimos a la emergencia de una generación de jóvenes que ha nacido en pleno auge de internet y que ha crecido incorporando las tecnologías tanto en su quehacer académico como en sus actividades de ocio y afectividad personales.

Ahora bien, la brecha digital en México impone una mirada crítica a la forma en que la población en general está accediendo a la tecnología. Los datos ${ }^{24}$ son contundentes: a) sólo el 48,3\% de los hogares cuenta con una línea telefónica; b) Ciudad de México tiene la mayor conectividad del país: el $43 \%$ de la población tiene computadora y el $36 \%$ de los capitalinos puede acceder a la red; c) por contraste, en Oaxaca, sólo 1 de cada 10 hogares tiene acceso a una computadora; y d) en México, hay 38.9 millones de personas que son usuarios de una computadora y 32.8 millones con acceso a internet.

Indudablemente hay un sector de sujetos excluido de ciertos circuitos informacionales, espacios de participación y de conformación gregaria que internet $y$, en particular, las redes sociales presuponen. No podemos soslayar este hecho, pues revela las profundas desigualdades que existen en México y, nos atrevemos a decir, en América Latina y que hoy solo son remarcadas por esta inclusión desigual. ${ }^{25}$

23 Esta investigación es resultado de un análisis longitudinal que cada año se realiza en más de 32 países, para conocer los hábitos y tendencias de las personas con respecto a las tecnologías de información y comunicación asociadas a internet. El estudio se llevó a cabo en México, específicamente en ciudades con más de 20 mil habitantes. El trabajo de campo fue realizado durante diciembre de 2010, enero y febrero de 2011, y el procesamiento de la información se concluyó en marzo. En México esta investigación está a cargo de Octavio Islas, investigador del Instituto Tecnológico y de Estudios Superiores de México, Campus Estado de México (ITESM/CEM).

24 Según los datos más recientes publicados por el INEGI (2011).

25 Término desarrollado por Reguillo (2011) que preferimos utilizar en vez de exclusión, para designar el proceso social que tiene lugar en el México 
García Canclini (2004) dice, en ese sentido, que la desigualdad, la diferencia y la desconexión son procesos que marcan hoy el devenir de los sujetos en un contexto globalizado. En referencia a un estudio de Amartya Sen, señala: «el acceso segmentado y desigual a las industrias culturales, sobre todo a los bienes interactivos que proveen información actualizada, ensancha las distancias en el acceso a la información oportuna y en el desarrollo de las facultades adaptativas que permiten mayores posibilidades de desarrollo personal, generando así menores posibilidades de integración socioeconómica efectiva» (García Canclini, 2004:82).

En ese sentido, según las cifras de un estudio reciente que realizamos entre jóvenes universitarios provenientes de instituciones de educación pública superior ${ }^{26}$ (Portillo, 2010), el 65,8\% cuenta con internet en casa, más de la mitad $(62,2 \%)$ le dedica sólo entre una y tres horas diarias a navegar por la red. La razón de las pocas horas de navegación entre este sector de jóvenes, se explica con un hecho relevante. La mayoría tiene computadora de escritorio en casa $(77,5 \%)$, lo cual supone un uso compartido: el 21,3\% afirma que comparte el uso de internet con al menos tres personas en casa. No son usuarios que posean la libertad de usar a su entera disposición ni la computadora ni la navegación por la red. Tienen, pues, un uso limitado a estas condicionantes estructurales. Estos datos contrastan con el estudio de Ortega y Ricaurte, quienes ubican a los nativos digitales mexicanos en el segmento de edad de entre quince y diecinueve años, estudiantes de escuelas privadas y ubicados en los niveles sociodemográficos medios y medios altos. Son sujetos perfectamente equipados, con acceso a la tecnología de punta: computadora, celular, ipod y videojuegos (Ortega y Ricaurte, 2011:44).

A pesar de las profundas desigualdades que existen en México, sostenemos que la emergencia de esta generación de jóvenes conectados resultará significativa en el futuro próximo. La llamamos generación 2.0, porque está desarrollando en las redes sociales nuevas formas de organización, participación y conformación gregaria. Los ca-

de hoy, en donde ciertas políticas neoliberales tienden a dificultar el acceso a los bienes y servicios por parte de amplios sectores de la población.

26 Proyecto de investigación PAPPIT de la UNAM (2009-2011), coordinado por Delia Crovi y como investigadoras asociadas Maricela Portillo y Luz María Garay. Los resultados de ese estudio saldrán publicados próximamente. 
sos de Egipto, Túnez, España son un atisbo de nuevas formas de participación política que, aun ocurriendo en otras latitudes, impactan las culturas juveniles y las nuevas formas de participación política en el mundo. En América Latina, el caso más emblemático es el de los pingüinos en Chile. Así pues, proponemos como intuición en nuestras indagaciones que la generación 2.0 compuesta fundamentalmente por jóvenes urbanos, de clase media y universitarios, impondrá nuevas formas de ejercer la ciudadanía. Los rasgos distintivos que componen el espíritu del tiempo de esta generación se caracterizan por «un contexto de innovación tecnológica en permanente recreación y dinamismo» (Ortega y Ricaurte, 2010). Los jóvenes son, como estas autoras señalan, verdaderos protagonistas de la revolución tecnológica del siglo XXI. Han llegado a poblar espacios desde los cuales hoy se empoderan y desarrollan estrategias de acción social y política: facebook, youtube, myspace, twitter, blogs, messenger, SMS (Ortega y Ricaurte, 2010). Entendemos que en México la inclusión desigual será un componente central de la generación 2.0. La potencia creadora de esta generación se muestra hoy en youtube y myspace, espacios en los cuales es posible encontrar ejemplos claros de broadcasting transmedial; se imponen temas que logran saltar a la agenda mediática y que obligan a su consecuente tematización. De igual manera, novedosas manifestaciones artísticas circulan en myspace. Estas tienen una impronta política clara, pues muestran un posicionamiento ideológico y ético de los nuevos creadores, desde el cual hacen circular su producción en esos circuitos virtuales, que impone, a su vez, nuevas formas de consumo, o reproducción musical.

\section{CONSIDERACIONES FINALES}

¿Existe una generación X en América Latina? Sostuvimos al inicio de este capítulo que las generaciones no son estructuras compactas, sino únicamente referentes simbólicos que identifican vagamente a los agentes socializados en unas mismas coordenadas temporales. Así pues, la heterogeneidad se muestra como una clave para pensar a la generación en este continente y nos obliga a cuestionarnos acerca de las formas culturales en que la posmodernidad latinoamericana se materializa. En principio, sostenemos que existe una generación que ha accedido a la juventud en los albores de este siglo compuesta por agentes socializados en una ubicación geopolítica que los hace competir asimétricamente con otros que lo han hecho en regiones en donde 
se ubican los centros que detentan el poder político y económico. Y que desde ahí, la generación X en América Latina muestra unas aristas difusas, pero que aún así pueden ser identificados con ciertos referentes simbólicos globales.

Insistimos, como lo hicimos en la introducción de este capítulo, que es necesario señalar que las fechas que enmarcan el nacimiento y fin de una generación deben asumirse únicamente como marcos referenciales y no en sentido estricto, debiéndose tomar en cuenta que una generación está marcada por los hechos históricos, políticos, mediáticos, culturales, tecnológicos, que perfilan la memoria, los gustos, las prácticas de los que son jóvenes en ese periodo y que les permiten construir una identidad generacional a partir del reconocimiento e identificación de esas vivencias compartidas. Precisamente, desde la perspectiva que prioriza la construcción juvenil de los actores juveniles desde «sus propios términos», esto es, desde los lugares en donde se ubican juventudes tan diversas y desiguales las coordenadas temporales que hacen a las generaciones se construyen desde las limitaciones estructurales a las que se enfrentan cotidianamente, a las que mixturan con historias más locales o más inmediatas y con elementos simbólicos de la cultura mundializada con los que sienten ciertas identificaciones como jóvenes. Esta heterogeneidad se traduce en distintos modos de ser joven, algunos más vinculados a la globalización - ya sea a través del mercado de trabajo, internet y la cultura digital, medios de comunicación o redes afectivas de migrantes cercanos- y otros más ligados a culturas regionales y/o locales.

Concluimos este ensayo planteando cinco tendencias centrales en la transición de la generación X a la generación @ en América Latina.

a) Desigualdad. Una característica central, según los casos presentados en este ensayo, es la profunda desigualdad social que marca estructuralmente a los sujetos jóvenes en nuestro continente. El acceso desigual a los bienes y servicios provoca tensiones constantes al interior de las generaciones. Estas tensiones obligan a la problematización de la categorización generacional latinoamericana. Si bien las generaciones no son estructuras compactas, como hemos dicho, en esta región lo son menos. Ocurre que están marcadas por la heterogeneidad. Las categorías juventud, clase, etnia y género no son neutras, conforman tipos específicos de desigualdades, producto de relaciones sociales y de poder históricamente constituidas en cada país, región y localidad y son usadas como herramientas para regular y normar asimétricamente las relaciones entre jóvenes/adultos, ricos y pobres, entre 
quienes poseen capital y poder y quienes no lo poseen, entre mestizos, blancos e indígenas, entre hombres y mujeres. Son construcciones socioculturales que han convertido las diferencias de edad o las biológicas del sexo en jerarquías de poder, de estatus y de ingresos a través de complejos sistemas de diferenciación y distinción culturales, que justifican constantemente la posición subordinada y dependiente de las mujeres, de los jóvenes, de los pobres, de las clases medias y populares, de los indígenas.

b) Interculturalidad. Entendemos que el siglo XXI evidencia nuevas circunstancias de la interculturalidad en términos de la aceptación o inclusión de la diferencia entre los modos de convivencia entre distintos grupos y jóvenes que pueden ser leídas en clave generacional. Enmarcadas en el contexto de una globalización asimétrica, resulta relevante el cuestionamiento acerca de cómo resolverán estas asimetrías sujetos socializados en unas mismas coordenadas temporales. Asumimos que la discusión generacional en América Latina pasará, necesariamente, por un debate acerca de la interculturalidad que incluya la aceptación de la diferencia. Y, de manera puntual, por la forma en que se resuelvan las diferencias culturales intrageneracionales en esta región.

c) Rural/indígena-urbano. Como es sabido, la población en América Latina tiene un fuerte componente indígena. Los casos mostrados en este ensayo, México y Chile, ilustran las tensiones generacionales que ocurren entre estos mundos rurales y/o indígenas y la escena urbana. Por un lado, constatamos la migración y consecuente visibilización de los jóvenes indios en las ciudades y, por otro, la irrupción de ciertas formas juveniles culturales urbanas que impactan los mundos rurales. Estas tensiones provocan importantes transformaciones socioculturales en relación a la construcción de las diversas juventudes en cada contexto sociocultural, de cómo se recuperen u olviden las tradiciones y se construyan nuevas formas de ser joven en las nuevas realidades migrantes y locales que la globalización está provocando desde hace un cuarto de siglo en las zonas de expulsión o de arribo de los jóvenes. Asimismo, estas nuevas realidades transforman ciertas prácticas sociales y permiten la emergencia de novedosos consumos culturales.

d) Local-global. La globalización, que ha traído importantes efectos en el plano de la cultura, se traduce en apropiaciones locales que impregnan de un cariz especial a la generación X en América Latina. Frente a la tendencia homogeneizante de la cultura global, cada localidad es tipificada por la hibridación cultural y la heterogeneidad, sujetas a fuerzas transnacionales/globales (Boyd-Barret, 1997). Una de sus 
expresiones más visibles tiene que ver con las hibridaciones de las prácticas culturales y sociales de los sujetos jóvenes, cuyos productos resultantes muestran transformaciones importantes en términos de la construcción identitaria juvenil contemporánea, que si bien manifiesta pertenencias, tiende a abrirse a la experiencia con unos otros distintos. Las imágenes culturales de lo juvenil que circulan en los circuitos del mainstream global no solo se reproducen a nivel local en reapropiaciones socioculturales específicas, sino que también manifiestan de manera acelerada estas apropiaciones locales y las devuelven al recolocar ciertas tendencias en otras latitudes. Los casos de los metaleros rurales o los jóvenes indios en las grandes urbes que gustan del $s k a$ y del punk, como vimos en este texto, nos muestran un atisbo de esta glocalization (Boyd-Barret, 1997).

e) La rearticulación de lo político a partir de la conectividad. Indudablemente internet y las redes sociales han venido a reconfigurar las formas de organización y participación. No es casual que la generación de jóvenes que ha crecido en esta era digital esté encontrando en estos espacios nuevos circuitos informacionales. Pero no solo eso. Han aprendido, a partir sobre todo de la emergencia de las redes sociales (facebook, twitter, etcétera), nuevas formas organizativas que hoy trascienden el espacio virtual y que en el caso de la generación pingüina en Chile o la generación 2.0 en México expresan atisbos de una nueva cultura política en América Latina. Aquí hay una clave distintiva de lo que ocurrirá con esta generación. Habrá que seguirle la pista a las formas distintas en que están accediendo a internet y participando en la cultura digital, en las redes sociales, impactando en la producción noticiosa; así como en la transformación de lo político en los contextos particulares de los países latinoamericanos, que tienen, no lo olvidemos, su propia especificidad. Entre los cambios más importantes que el espacio virtual está propiciando en la construcción de los jóvenes como actores sociales, está «la gestión del yo» o la producción de la presencia y visibilización juvenil de maneras más individuales a las maneras colectivas-grupales del siglo XX. 


\section{PoST SCRIPTUM}

Al finalizar este escrito, a mediados de 2011, jóvenes estudiantes chilenos y jóvenes pacifistas mexicanos están en pie de guerra contra enemigos distintos pero igualmente poderosos: el Estado neoliberal y las redes del narcotráfico. Todos ellos usan facebook y otras redes sociales para divertirse y comunicarse entre ellos, pero también para organizarse y protestar. Todos ellos son hijos virtuales de la generación X, cuya existencia real en América Latina hemos discutido en este texto, pero cuya existencia simbólica queda demostrada por sus efectos en la educación sentimental y tecnológica de las nuevas generaciones, que de repente descubren sin saberlo que en el fondo quizá Douglas Coupland no estaba tan equivocado.

CiUdAd DE MÉXICO (MÉXICO), JULIO DE 2011

RECIBIDO: SEPTIEMBRE 2012 ACEPTADO: NOVIEMBRE 2012

\section{REFERENCIAS BIBLIOGRÁFICAS}

AGUILERA, ÓSCAR (2010): «Cultura política y política de las culturas juveniles». Utopía y Praxis Latinoamericana, 15 (50), Maracaibo.

(2003): «Jóvenes y política en el Chile de la transición 1988-2000: análisis de los discursos sociales sobre juventud». Tesis de Magíster en Antropología, Universidad Autónoma de Barcelona.

ALBERONI, FRANCESCO (1984): Movimiento e institución. Teoría general. Madrid: Editorial Nacional.

AMIPCI (2011): Informe anual sobre internet en México, 2010. México: Asociación Mexicana de Internet.

AmTMANN, CARLOS et al. (1998): La pequeña agricultura en la Región de Los Lagos. Valdivia: Ediciones de la Universidad Austral de Chile.

BOYD-BARRET, OLIVER (1997): «International Communications and Globalization: Contradictions and Directions». In A. MoHAMMADI (ed.): International Communication and Globalization. Londres/New Delhi, Sage.

CAmus, Albert (1957): El mito de Sísifo. El hombre rebelde. Buenos Aires: Editorial Losada.

ChONCHOL, JACQUeS (1996): Sistemas agrarios en América Latina. De la etapa prehispánica a la modernización conservadora. México: FCE.

DE CERTEAU, MICHAEL (1995): La toma de la palabra y otros escritos políticos. México: Universidad Iberoamericana. 
De la MAZA, GonZALO (1998): «Situación socioeconómica y cultural de los jóvenes temporeros de la VI Región». Informe Final. Santiago: Instituto Nacional de la Juventud.

Díaz, Cecilia y ESTEBAn DuRÁn (1986): Los jóvenes de campo chileno: una identidad fragmentada. Santiago: Editorial GIA.

ESCALANTE, YURY (S/F): La exclusión indígena de la membresía urbana. Disponible en: http://www.indigenasdf.org.mx/convivencia.php.

FeIXA, CARLES (2005): «Generation @. Youth in the Digital Era». In D. DODD (ed.): Whose Culture Is It? Trans-generational approaches to Culture. Budapest: The Budapest Observatory.

(2000): «Generación @. La juventud en la era digital». Nómadas $\mathrm{N}^{\circ} 13$. Bogotá. (1997): «Más allá de la generación X». Topodrilo N44. México.

y YANKO GONZÁLEZ (2003): «The Socio-Cultural Construction of Youth in Latin America: Achievements and Failures». In G. HOLM \& H. HELVE (eds.): Contemporary Youth Research: Local Expressions and Global Connections. Londres: Ashgate.

— $\mathrm{y}-$ (2005): «Territorios baldíos: identidades juveniles indígenas y rurales en América Latina». Papers, Revista de Sociología. Barcelona.

GAMA, Federico (2009): Mazahuacholoskatopunk. México: Instituto Mexicano de la Juventud.

García CANCLINI, NÉSTOR (2004): Diferentes, desiguales y desconectados. Mapas de la interculturalidad, Barcelona: Gedisa.

GAUSA, MANUEL (2002): Singular Housing. Barcelona: Actar.

GONZÁLEZ, YANKO (2004). «Óxidos de identidad: memoria y juventud rural en el sur de Chile (1935-2003)». Tesis doctoral. Universidad Autónoma de Barcelona.

— (2003): «Juventud rural: trayectorias teóricas y dilemas identitarios». Nueva Antropología, México DF.

HANNERZ, ULF (1998): «El papel cultural de las ciudades mundiales». En Conexiones trasnacionales. Cultura, gente, lugares. Valencia: Ediciones Cátedra.

- (1986): Exploración de la ciudad. México: FCE.

INEGI (2011): Censo 2010. México: Instituto Nacional de Estadística, Geografía e Informática.

LECHNER, NORBERT (1988): Cultura política y democratización. Buenos Aires: CLACSO.

MARTÍN-BARBERO, JESÚS (2002): «Jóvenes: comunicación e identidad». Pensar Iberoamérica.

Disponible en: www.campusoei.org/pensariberoamerica/ric00a03.htm. (1996): «De la ciudad mediada a la ciudad virtual, transformaciones radicales en marcha». Telos, Madrid.

MORA, TERESA et al. (2004): «La etnografía de los grupos originarios y los inmigrantes indígenas de la ciudad de México». En PABLO YANES, 
VIRGINIA MOLINA y ÓSCAR GoNZÁLEZ (coordinadores): Ciudad, pueblos indígenas, etnicidad. México: Universidad de la Ciudad de México.

ORTEGA, Z. (2001): «El derecho triqui de Xuman Li en el medio urbano». Revista Crítica.

ORTEGA Y GASSET, José (1970): La rebelión de las masas. Madrid: Espasa Calpe.

ORTEGa, ENEDINA y PAOLA RICAURTE (2011): «Jóvenes nativos digitales: mitos sobre la competencia tecnológica». Diario de campo, México.

PÉREZ RUÍZ, MAYA (coordinadora) (2008): Jóvenes indígenas y globalización en América Latina. México: INAH.

PORTILlO, MARICELA (2010): «Usos y apropiaciones tecnológicas de los estudiantes universitarios mexicanos». Ponencia presentada en la Asociación Latinoamericana de Investigadores de la Comunicación (ALAIC), septiembre, Bogotá.

REGUILLO, RosSANA (1998): «El año dos mil, ética, política y estéticas: imaginarios, adscripciones y prácticas juveniles». En HUMBERTO CUBIDES, MARÍA CRISTINA LAVERDE, CARLOS VALDERRAMA y MARIO MARGULIS: Viviendo a toda. Jóvenes, territorios culturales y nuevas sensibilidades. Bogotá: Universidad Central, Siglo del Hombre Editores.

Rosaldo, Renato (1991): Cultura y verdad. Nueva propuesta de análisis social. México: Grijalbo y CNCA.

SÁNCHEZ CHÁVEZ, ÁNGEL (2009): «Jóvenes, identidades migrantes, subcultura y performance». Tesis para obtener el grado de ingeniero agrónomo. Chapingo, Estado de México, Universidad Autónoma Chapingo.

Urteaga Castro-Pozo, Maritza (2008): «Jóvenes e indios en el México contemporáneo». Revista Latinoamericana de Ciencias Sociales, Niñez y Juventud. Manizales.

_ (2007): «La construcción juvenil de la realidad. Jóvenes mexicanos contemporáneos». Tesis para optar al grado de doctora en ciencias antropológicas. México: UAMI.

VALENZUELA, JosÉ MANUEl (1998): «Identidades juveniles». En HuMBERTO Cubides, María Cristina LaVerde, Carlos ValderRama y Mario MARGULIS: Viviendo a toda. Jóvenes, territorios culturales y nuevas sensibilidades. Bogotá: Universidad Central, Siglo del Hombre Editores.

Vergara, Miguel Ángel (2005): «Desde la posciudad, repensando lo urbano y la antropología. Antropología urbana como producción simbólica», Antropologías y estudios de la ciudad.

WiLlis, PAUL; S. JONES et al. (1990): Common Culture: Symbolic Work at Play in The Everyday Cultures of the Young. Buckingham: Open University Press. 